\title{
Control Theory and System Dynamics Simulations of Electric Vehicle Market Penetration in South Africa
}

\author{
Nalini Sooknanan Pillay ${ }^{1,2(\bowtie)}$, Alan Colin Brent ${ }^{1,2}$, \\ and Josephine Kaviti Musango ${ }^{1,2}$ \\ 1 Department of Industrial Engineering, Stellenbosch University, \\ Private Bag X1, Matieland, Stellenbosch 7602, South Africa \\ acb@sun.ac.za, Josephine.musango@spl.sun.ac.za \\ ${ }^{2}$ Eskom SOC, Research Testing and Development, \\ Private Bag 40175, Cleveland 2022, South Africa \\ Pllayna@eskom.co.za
}

\begin{abstract}
Economic development shares interdependence with energy investment, a complex interaction of systems. Thus, advanced modelling tools are required to support the development of strategic integrated energy plans, inclusive of the technological complexities in the electricity value chain. This paper looks at a system dynamics modelling approach with elements of control systems engineering to determine the impact of the electric vehicle (EV) technology market penetration on the electricity demand profile and the related environmental impact in the energy and transport sectors in South Africa. Results indicate that the approach provided a robust framework in which to design the model and conduct sensitivity analyses of additional EVs entering the system due to the feedback loops inherent in the system structure.
\end{abstract}

Keywords: System dynamics $\cdot$ Control theory $\cdot$ Electric vehicles

\section{Introduction}

Future investments in electricity generation technologies in South Africa will depend on the dynamics linked to the country's socio-economic development and the environment, against a backdrop of policies and regulations ensuring compliance and direction. The volatility in the power generation value chain is further impacted by disruptive technologies such as electric vehicles, identified by the South African Department of Transport in the Green Transport Strategy, as a possible mitigation mechanism against climate change. The expected target for South Africa is 2.9 million batter electric vehicles (BEVs) by 2050 to reduce carbon emissions in the transport sector through substitution with the internal combustion engine vehicles (ICEVs) [1]. The target was expected to be affected by various drivers identified in the course of this study including BEV reputation, charging station infrastructure, "range anxiety" and the purchase price [2]. 
The emergent behavior of these driving elements in the system was expected to contribute an additional number of BEVs to the target, requiring structural feedback loops to allow for the non-linear system behavior [3]. Control engineering based on feedback theory [4], as well as system dynamics modelling were identified as having the necessary mathematical frameworks which could provision the secondary impacts from reiterative loop behavior in a dynamic environment. System dynamics modelling was developed in the mid-1950s by Jay Forrester, with the first structure consisting of hand-drawn stock-flow-feedback loops, illustrating counterintuitive system behavior related to policy related decisions affecting attrition in General Electric [5]. The method developed from his knowledge on control theory. This paper looks at the common components in both control systems engineering and system dynamics modelling and explains the leverage points and process used in the system dynamics methodology to develop a detailed long-term electricity strategic electric vehicle (E-StratBEV) simulator. The completed E-StratBEV simulator was used for scenario analysis to determine the impact of BEVs on electricity consumption and carbon emissions in the transport and electricity sectors.

\subsection{Non-linearity in Electrical Energy Systems}

Non-linear relationships identified between variables in electrical energy systems have challenged the application of conventional econometric methods and linear programming techniques. For example, the resultant impact on energy consumption in the economic sectors due to changes in the price of electricity. When the electricity price decreases, there is an increase in the use of electricity. This trend then reaches a saturation level due to physical system constraints and/or production capacity maximization even if the price of electricity further decreases.

Together with non-linearity, the system has variables subject to time lags and delays which also need to be accounted for. For example, a decision to build a new power station is followed by a time lag, involving environmental impact assessments, regulatory aspects, and equipment procurement and commissioning, as well as political influences such as strikes.

This non-linearity required mathematical representation of the variables within electrical energy systems which reflected feedback. Feedback behavior can be modelled through control systems engineering (based on feedback theory and system analysis) and system dynamics modelling.

\subsection{Feedback Behaviour in Control Engineering and System Dynamics}

Both control systems engineering and system dynamics modelling leverage on the power of mathematical modelling through algebraic equations and integration. This allows the design of model structures which are methodical but more importantly, it allows the ability to build in qualitative and quantitative elements of feedback inherent in most systems. The input-output relationship in a process within a system represents the cause-effect relationships, also reflected through tools such causal loop diagrams [6] in the system dynamics modelling process. 
Figure 1 shows the diagrammatic differences in linear and feedback views of the world, incorporating control theory and extending into the system dynamics realm. In Fig. 1 the linear open-loop view of the world (A) involves obtaining information about a problem the taking an action after which a solution or result emerges (generally linear optimization, least cost modelling approach). The closed loop feedback view of the world (B) is the control theory backbone on which system dynamics advanced.

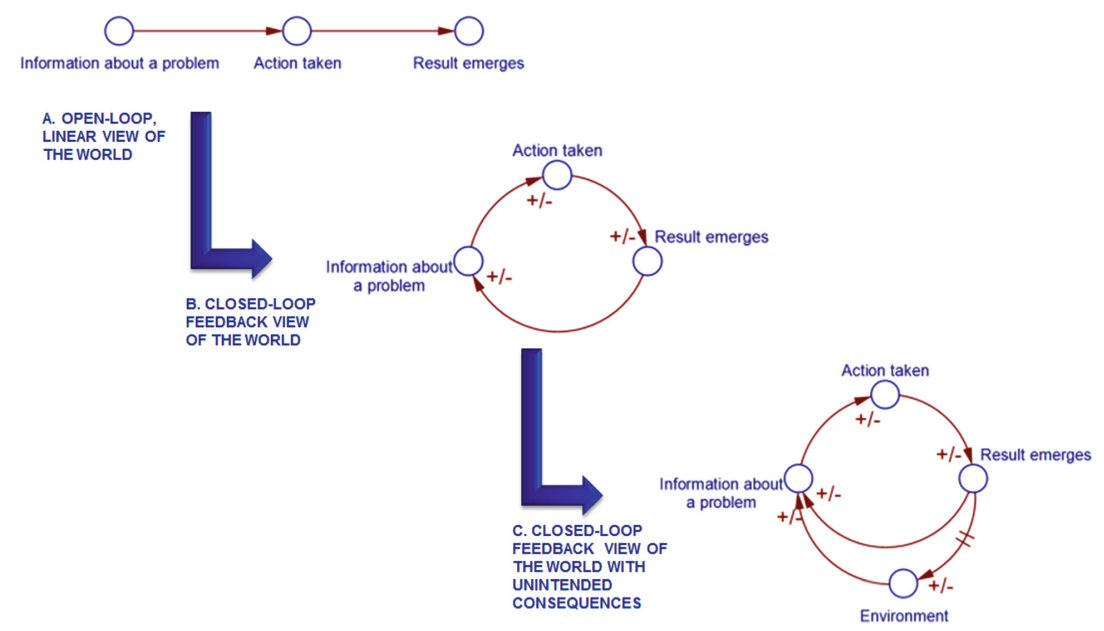

Fig. 1. Linear and feedback views of the world

This closed-loop feedback view of the world suggests that information obtained about a problem results in an action being taken and a result emerging, however, the dynamic nature of the system means that the resultant behavior (after action was taken) will have changed the original knowledge on the problem, which then informs a new action and so the loop continues. In system dynamics modelling, after a result emerges, the environment is also expected to change $(\mathrm{C})$, linked to the emergence of unintended consequences. Obtaining leverage points and intuitive insights to affect the system changes will then be required and is usually supplemented by systems thinking tools to understand root cause behavior as opposed to symptomatic treatment of system problems. "End-of pipe" approaches result in perceived causes which yield reactive solutions. In the case of a systems thinking approach, patterns of behavior are determined from the events occurring and the root cause identification will result in a corrective solution.

In this study, the complexity of the interaction between qualitative and quantitative variables which were expected to impact the external environment over time and through feedback behavior required a detailed modelling process for descriptive analysis. Thus an adapted system dynamics approach requiring more contextualization than a control engineering mathematical platform was followed. 


\subsection{System Dynamics Modelling Process}

System dynamics (SD) modelling allows for descriptive analysis facilitating root cause understanding based on non-pure system responses. The primary steps include problem identification and system conceptualization, model formulation, model development and testing, and policy analysis. Since 2010, this method was applied to various system problems across the electricity value chain, in Eskom, a State Owned Company (SOC) e.g. Impact of Income Distribution on Electricity Consumption [7]. Through the years, it became apparent that the successful implementation and application of the system dynamics models was dependent not only on structural model development, but also on the effectiveness of engagements with stakeholders, a comprehensive conceptto-context process, system analysis and model communication and knowledge transfer. The steps of this amended SD approach are detailed in Table 1 [8].

Table 1. Steps in the adapted system dynamics modelling approach [8].

\begin{tabular}{|c|c|c|}
\hline No. & Step & Elements of the step \\
\hline 1 & $\begin{array}{l}\text { Inception of project and setting } \\
\text { the focusing question }\end{array}$ & $\begin{array}{l}\text { - Understand the application and limitation of SD } \\
\text { modelling, } \\
\text { - Establish the focusing question linked to the system } \\
\text { problem, } \\
\text { - Identify members to form a working group }\end{array}$ \\
\hline 2 & Concept to context & $\begin{array}{l}\text { - Determine the modelling timeframe, } \\
\text { - Understand the historical trends of variables, } \\
\text { - Develop a diagrammatic framework (System architecture } \\
\text { map) with upstream and downstream variables }\end{array}$ \\
\hline 3 & Boundary setting & $\begin{array}{l}\text { - Develop causal loop diagrams, } \\
\text { - Define a model boundary chart (with endogenous (input) } \\
\text { and exogenous (output) variables) }\end{array}$ \\
\hline 4 & System analysis & $\begin{array}{l}\text { - Include preliminary computations ranging from } \\
\text { statistical analysis to programming and data mining }\end{array}$ \\
\hline 5 & Model development and design & $\begin{array}{l}\text { - Determine the modules and sub-modules to be } \\
\text { developed, } \\
\text { - Decide on the SD modelling software, } \\
\text { - Determine the state variables, initial conditions of stocks } \\
\text { and parameterization, } \\
\text { - Establish the mathematical linkages of variables, } \\
\text { - Develop engagement platforms to run relevant scenario } \\
\text { analysis }\end{array}$ \\
\hline 6 & Validation and policy insights & $\begin{array}{l}\text { - Test the scenarios against the relevant policies, } \\
\text { - Validation (structural, empirical, behavioral and } \\
\text { application) }\end{array}$ \\
\hline 7 & Model handover & $\begin{array}{l}\text { - Run a series of training workshops for knowledge } \\
\text { transfer and to equip model custodian with skills }\end{array}$ \\
\hline 8 & $\begin{array}{l}\text { Model maintenance and } \\
\text { updates }\end{array}$ & $\begin{array}{l}\text { - Short term support to the model custodian through } \\
\text { follow up meetings, } \\
\text { - Data updates and minor structural changes are included } \\
\text { as part of the model maintenance }\end{array}$ \\
\hline
\end{tabular}


Some of the key elements of Step 2 include the development of the diagrammatic framework or system architecture map (SAM). The SAM does not display cause and effect relationships or directional quantities but includes a flow of elements impacting the system experiencing the problem. It has proven to be a valuable tool for stakeholder engagements especially in instances where the stakeholders do not want the technical detail and provides strategic insight to the bigger picture based on mental models, as well as theoretical and empirical linkages. The SAM constructed for this case study is shown in Fig. 2.

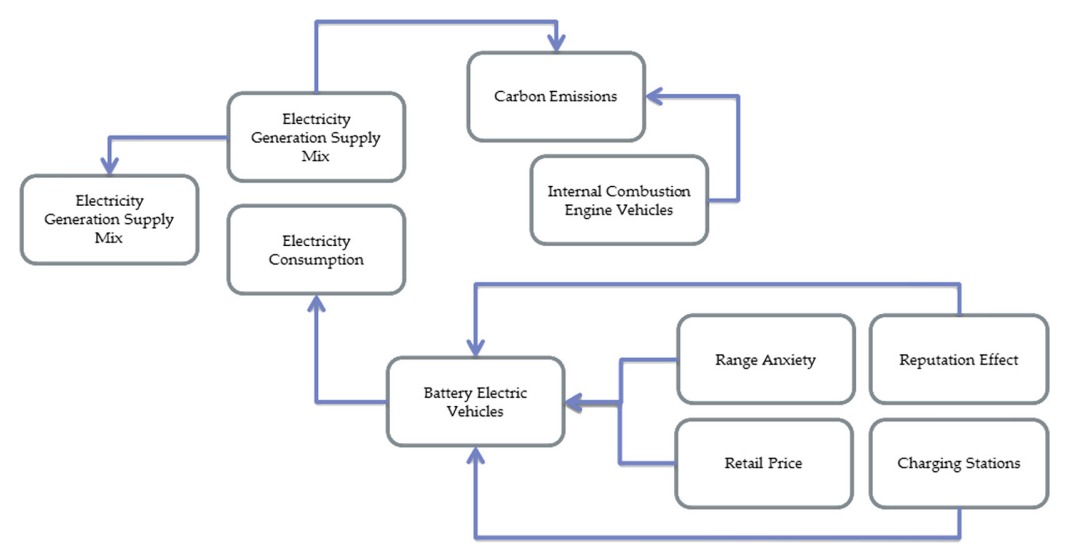

Fig. 2. System architecture map

The SAM includes those elements such as the drivers impacting BEVs, as well as the components which would have to be translated into structural modules such as the electricity supply mix (currently a coal heavy supply mix with operational performance factors), electricity consumption (with additional charging requirements from electric vehicle market penetration) and environmental impact (carbon emissions in the electricity and transport sectors). Additional considerations in the SD modelling process includes the constitution of the work group team in developing the causal loop diagram (CLD) (Step 3), since the quality will be dependent on the collective knowledge and experience of the members.

Preliminary system analysis (Step 4), assists the validation process since involves calculations with historical data which can be compared to simulation runs to confirm no accumulation of integration errors or incorrect mathematical structural linkages in the model development step. 


\section{Application and Methodology of System Dynamics to Electric Vehicle Market Penetration}

\subsection{The Context for the EV Case Study}

The drivers influencing consumer choice for purchasing BEVs include tax incentives, increased charging infrastructure, longer driving ranges (with reduced "range anxiety"), lower purchase prices, fuel efficiency, speed and acceleration, vehicle variety and reputation effects, as well as policy mechanisms linked to climate change mitigation. Literature indicates that these drivers are region specific [9]. Based on data and information obtained from a collaborative three year BEV study between Eskom SOC and Nissan [10], the drivers chosen for this study included range anxiety, purchase price, reputation effect and charging stations. Based on the steps followed in the SD modelling process, it was expected that the drivers would introduce a secondary impact which would result in an additional number of BEVs to targets in the scenarios for the E-StratBEV.

Table 2 includes the modules and sub-modules developed using iSee Stella system dynamics software. The modelling timeframe was from 1993 until 2040.

Table 2. Modules for the E-StratBEV.

\begin{tabular}{l|l|l}
\hline & Module & Sub-module \\
\hline 1 & $\begin{array}{l}\text { Electricity generation } \\
\text { supply mix }\end{array}$ & $\begin{array}{l}\text { - Installed electricity capacity with performance factors } \\
\text { - Electricity sector } \mathrm{CO}_{2} \text { emissions }\end{array}$ \\
\hline 2 & Electricity demand & $\begin{array}{l}\text { - Residential electricity consumption } \\
\text { - Electricity demand from EVs }\end{array}$ \\
\hline 3 & ICEVs & $\begin{array}{l}\text { - ICEVs per province } \\
\text { - Transport sector } \mathrm{CO}_{2} \text { emissions } \\
\text { - Fuel efficiency } \\
\text { - Scrappage }\end{array}$ \\
\hline 4 & EVs & $\begin{array}{l}\text { - BEVs distributed per province } \\
\text { - Feedback loops with the impact of drivers such as range } \\
\text { anxiety, purchase price, reputation effect and charging stations }\end{array}$ \\
\hline
\end{tabular}

The targets for the study start penetrating the South African market and substituting with ICEVs from 2019. The study used a Low Growth scenario of 233,700 BEVs by 2040 based on a GDP parametric and Bloomberg New Energy Finance forecast of 41 million global electric vehicle sales by 2040 [11]. The High Growth scenario is 2.39 million EVs by 2040 based on South Africa's pledge to support the Paris Agreement on Climate Change commitments in April 2016, signed by the Minister of Environmental Affairs [12]. 


\subsection{Mathematical Prerequisites}

Due to the non-linear relationship between variables in the E-StratBEV, forecasted trends were made using the logistics curve equation specified by Meyer [13], shown in Eq. 1, which allows for asymptotic conversion to lower values, by specifying a negative value for $U_{1}$, or a positive stabilizing non-zero value by retaining a positive value for $U_{1}$.

$$
P(t)=U_{0}+\frac{U_{I}}{I+\exp \left[\underline{\operatorname{mog}}\left[-c\left(t-t_{0}\right)\right]\right.}
$$

where $P$ is the dependent variable and $P(t)$ is a function of time $t ; U_{0}$ is the zero offset; $U_{1}$ is the ultimate increase (or decrease) above $\mathrm{U}_{0}$, modelled using a $\mathrm{S}$-curve; $c$ is a growth rate exponent that determines the maximum slope of the S-curve; and $t_{0}$ is the time at which the maximum slope is reached (inflection point).

The performance measures and total electricity generated in the module for the electricity supply mix used weighted average performance formulas [14], shown in Eq. 2.

$$
M=\frac{\sum m_{i} C_{i}}{\sum C_{i}}
$$

where $i$ is the power station, $M$ is the power station's capacity weighted average of performance measure $m ; m_{i}$ is the performance measure for the power station (e.g. load factor); and $C_{i}$ is the capacity of station, $i$.

Regression equations were used to determine the relationship between certain variables for mathematical structuring in the model e.g. the forecasted battery technology improvement expectations with range anxiety (Eq. 3).

$$
\text { Range Anxiety }(y)=-0.001\left(x^{2}\right)+0.1886(x)+85.035
$$

The rate equations and defining the variable parameters and initial values, for the stock flow structures in the model were based on the "Principle of Accumulation", represented by differential Eq. 4.

$$
\text { Stock }(t)=\operatorname{Stock}(t-d t)+(\text { Inflow Rate }- \text { Outflow rate }) x d t
$$

The differential equation tells us that the Stock at time $t$ is found from the Stock at a previous point in time, $(t-d t)$, by adding the net quantity accumulated as the result of the inflow and outflow during the period $d t$, basically a first order differential equation [15].

\footnotetext{
${ }^{1}$ Principle of Accumulation states that "all dynamic behaviour in the world occurs when flows accumulate in stocks".
} 


\subsection{Initial Conditions and Targets}

The fuel consumption of $21 \mathrm{kWh}$ per $100 \mathrm{~km}$ and a daily average distance of $71 \mathrm{~km}$ was used for the BEVs based on the Eskom-Nissan pilot study [10]. Based on the national average vehicle age of $\sim 11$ years, a scrappage rate of $13.84 \%$ was built into the simulator. An annual fuel efficiency improvement of $1 \%$ per year for new ICEVs from year 2018 was estimated, based on the Vehicle Parc Model developed by the Energy Research Centre [14] with a sliding scale fuel efficiency improvement trend using S-curves. The initial fuel economy for petrol ICEVs was $0.084 \mathrm{~L} / \mathrm{km}$ with an emission factor of $2.27 \mathrm{~kg} / \mathrm{L} \mathrm{CO}$, while for the diesel ICEVs a value of $0.063 \mathrm{~L} / \mathrm{km}$ was used with an emissions factor of $2.68 \mathrm{~kg} / \mathrm{L} \mathrm{CO}_{2}$.

\subsection{Model Development and Design}

Figure 3 shows one of the feedback structures built in the model structure which links range anxiety to battery capacity. As battery technology improves and the range gets higher, consumer range anxiety decreases.

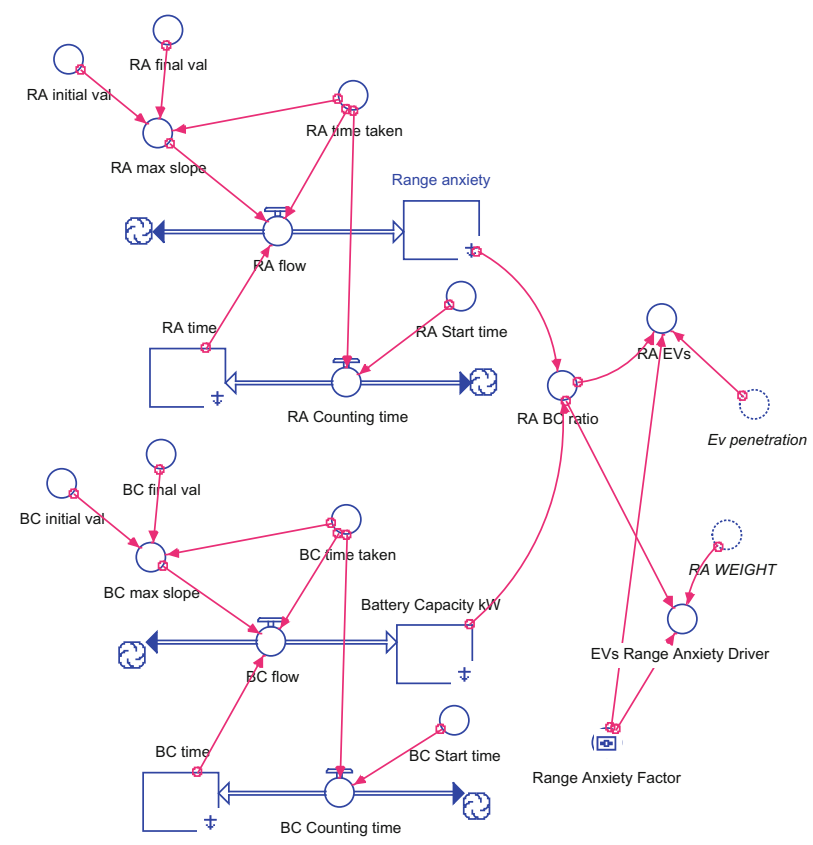

Fig. 3. Model structure of range anxiety and battery capacity

The stock value of Range Anxiety depletes over time as the Battery Capacity stock increases (improves) which then introduces an additional number of BEVs which are then added to the original BEV target. Feedback structures were also developed linking a reduction in purchase price, increase in charging stations and improvement in BEV reputation to an additional number of BEVs entering the system. 


\section{Results and Discussion}

The impact of BEVs on residential electricity consumption is shown in Table 3 with an overall increase in residential electricity consumption of $1.41 \%$ for the Low Growth scenario and $14.46 \%$ for the High Growth scenario in 2040.

Table 3. Impact of BEV market penetration on residential electricity consumption [8].

\begin{tabular}{l|l|l|l}
\hline $\begin{array}{l}\text { BEV target impact on residential electricity consumption } \\
(\% \text { increase })\end{array}$ & 2019 & 2030 & 2040 \\
\hline Low Growth & $0.02 \%$ & $0.98 \%$ & $1.41 \%$ \\
\hline High Growth & $0.17 \%$ & $10 \%$ & $14.46 \%$ \\
\hline
\end{tabular}

BEV drivers added a further cumulative total of 270 GWh from 2019 until 2040 while the High Growth BEV drivers add a further 2,764 GWh to the residential consumption [8]. The number of additional BEVs for the growth scenarios is shown in Fig. 4 with the largest impact due to the purchase price driver.

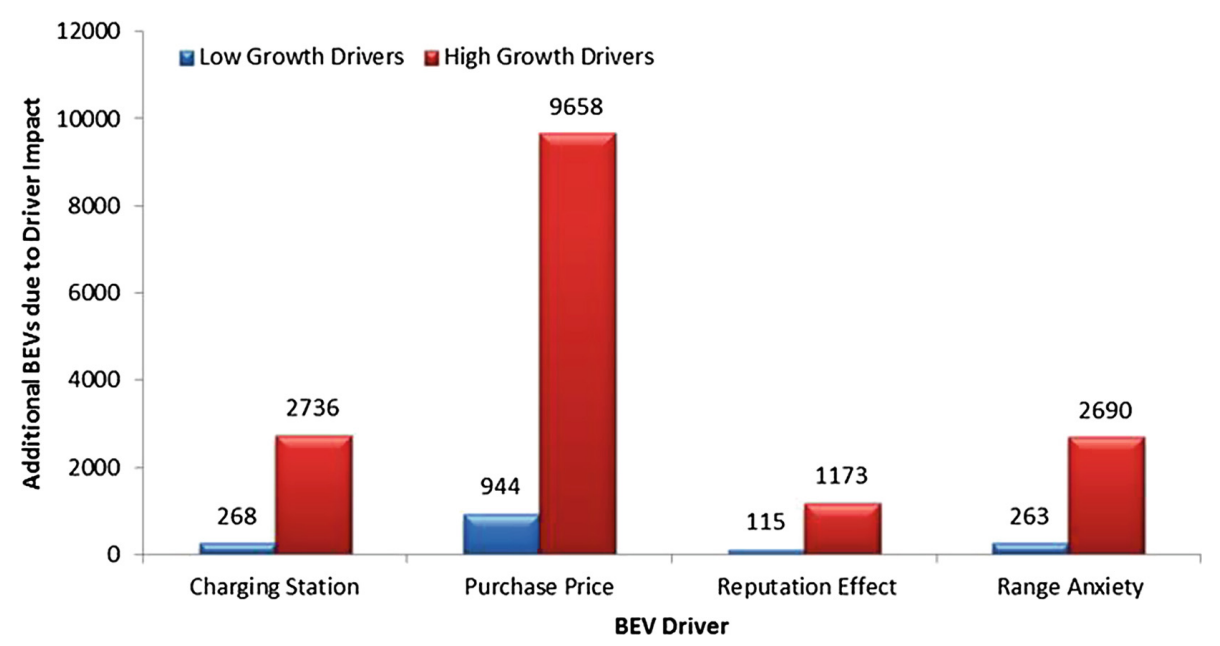

Fig. 4. BEVs introduced into the system through feedback loops [8]

For a coal heavy supply mix, the cumulative carbon emissions from 2019 until 2040, for the Low Growth scenario resulted in an increase of 10.04 Mton in the electricity sector and a 8.21 Mton decrease in the transport sector. The High Growth scenario resulted in 102.86 Mton cumulative carbon emissions in the electricity sector for a coal heavy supply mix and a decrease of 84.98 Mton in the transport sector. 


\section{Conclusions and Recommendations}

The most dominant feedback behavior was introduced by decreasing the purchase price of BEVs.

Unless the electricity generation mix changes from a coal heavy to a renewables heavy future supply, the net benefit from the emission reduction in the transport sector versus the emission increase in the electricity sector is negligible. Well-to-wheel calculations may also impact the calculations since tank-to-wheel values were used for emission calculations.

The use of the system dynamics methodology to develop E-StratBEV allowed sensitivity and scenario analysis of hundreds of causally linked qualitative and quantitative dependencies, and allowed the structural linkage of feedback loops involved in additional BEVs due to the various drivers. Although control engineering could have provided the necessary mathematical feedback structures for the BEV driver impact, the key advantage of following the system dynamics methodology was the additional steps in the modelling process which allowed for an in-depth contextualization of the system problem to frame the elements within the system boundary.

Acknowledgments. The authors wish to acknowledge the Eskom e-Mobility team and the Eskom System Dynamics CoE.

\section{References}

1. DOT: Draft Green Transport Strategy: (2017-2050). Chemical \& Allied Industries Association, August 2016. https://www.caia.co.za/wp-content/uploads/2016/08/Draft\% 20GTS\%20Revised\%20v5.pdf. 17 Jan 2018

2. Coffman, M., Bernstein, P., Wee, S.: Factors affecting EV adoption: a literature review and EV forecast for Hawaii. University of Central Florida, Florida, April 2015

3. Forrester, J.W.: Learning Through System Dynamics as Preparation for the 21st Century. MIT, Cambridge (2009)

4. IEEE Control Systems Society: Control and Control History (n.d). http://www.ieeecss.org/ publications/tac/control-control-history. 26 July 2018

5. Forrester, J.W.: Industrial Dynamics. MIT Press, Cambridge (1961)

6. Haraldsson, H.V.: Introduction to Systems and Causal Loop Diagrams. Lunds University, Sweden, January 2000

7. Pillay, N.S., Nel, W., Cohen, B.: A system dynamics approach to exploring the relationship between income distribution and residential electricity consumption. In: 32nd International System Dynamics Conference. System Dynamics Society (2014)

8. Pillay, N.S., Brent, A.C., Musango, J.K.: An adapted system dynamics approach to determine the linkage between battery electric vehicle affordability and real disposable income in South Africa. In: 29th Annual Conference of SAIIE, SAIIE, Stellenbosch, October 2018

9. Bessenbach, N., Wallrapp, S.: Why do Consumers resist buying Electric Vehicles. An empirical Study of Innovation Perception and the Effect of Consumer Characteristics, Innovation Exposure and Buying Incentives. Copenhagen Business School (2013)

10. Langley, P.: Electric Vehicle Results. Report 1789591. Eskom SOC. Johannesburg, South Africa (2016) 
11. Randall, T.: Here's How Electric Cars Will Cause the Next Oil Crisis. Bloomberg New Energy Finance, 25 February 2016. https://www.bloomberg.com/features/2016-ev-oilcrisis/. 12 June 2018

12. DEA: South Africa joins Nations of the World in ratifying the Paris Agreement on Climate Change. Department of Environmental Affairs, November 2016. https://www.environment. gov.za/mediarelease/southafrica_ratifies_parisagreement. 23 May 2018

13. Meyer, P.: Bi-logistic growth. Technol. Forecast. Soc. Chang. 47, 89-102 (1994)

14. Merven, B., Stone, A., Hughes, A., Cohen, B.: Quantifying the energy needs of the transport sector for South Africa: a bottom-up model. University of Cape Town. Energy Research Centre (2012)

15. Fuchs, H.U.: System Dynamics Modelling in Science and Engineering. University of Puerto Rico, Mayaguez, December 2006 